\title{
PAISAGENS DESCRITIVAS: O REGISTRO DE LUGARES POSSÍVEIS NA OBRA DE FRANS POST (1612-1680)
} DESCRIPTIVE LANDSCAPES:
RECORDING POSSIBLE PLACES ON THE WORK OF
FRANS POST (1612-1680)

Daiana Schröpel ${ }^{1}$ 


\section{Resumo}

O presente artigo analisa três obras do artista holandês Frans Post (16121680), integrante da missão científica trazida pelo Conde Maurício de Nassau ao Brasil no século XVII. As obras - designadas O Rio São Francisco (1638), Forte Maurício no Rio São Francisco (1647) e Cachoeira de Paulo Afonso (1647) - são abordadas, simultaneamente, sob perspectiva científica e como representações pictóricas. Desenvolve-se a noção lugares possiveis, conforme proposta por Svetlana Alpers (1987), para a compreensão das imagens criadas por Post in loco em situação de artista viajante e, posteriormente, das representações criadas a partir do repertório de formas, constituído ao longo de sua estadia no Brasil. Pretende-se, desse modo, alargar o entendimento sobre a obra daquele artista, conservando seu duplo estatuto, a saber, como registros visuais descritivos e como imagens construídas entre realidade e artifício.

Palavras-chave: Frans Post; paisagem descritiva; registro; lugares possíveis.

\section{Abstract}

This article analyzes three works by the Dutch artist Frans Post (1612-1680), a member of the scientific mission brought by Count Maurício de Nassau to Brazil in the 17th century. The works - called The River São Francisco (1638), Forte Maurício on the São Francisco River (1647) and Paulo Afonso Waterfall (1647) - are simultaneously approached from a scientific perspective and as pictorial representations. The notion of possible places, as proposed by Svetlana Alpers (1987), is developed aiming the understanding of the images created by Post in loco as a traveling artist and, later, of the representations created from the repertoire of forms, constituted during his stay in Brazil. In this way, it is intended to broaden the understanding of the artist's work, maintaining its dual status, as descriptive visual records and as images constructed between reality and artifice.

Keywords: Frans Post; descriptive landscape; recording; possible places.

ISSN: 2175-2346

${ }^{1}$ dschropel@gmail.com 


\section{Introdução}

No século XVII, uma comitiva composta por artistas e cientistas desembarcou no Nordeste brasileiro a contrato do Conde João Maurício de Nassau-Siegen (16041679) com o objetivo de observar, coletar e registrar elementos da fauna, da flora, da topografia e os tipos étnicos do "Brasil holandês". Dentre os artistas que compunham tal missão artística e científica - considerada o primeiro empreendimento dessa espécie realizado no Brasil -, destacam-se as figuras de Albert Eckhout (1610-1665) e Frans Post (1612-1680), cujos desenhos e pinturas constituem documentos iconográficos centrais na investigação sobre a construção da identidade brasileira em seus aspectos políticos, históricos, sociais e culturais. Suas obras representam uma busca sistemática pela assimilação do Novo Mundo e simultânea tradução de tal repertório em formas suscetíveis de compreensão na Europa. Portanto, elas não estão isentas de valores culturais.

É, sobretudo, na obra de Frans Post em que a construção imagética e imaginária da paisagem brasileira se manifesta de modo significativo. A partir da análise comparativa de três obras pontuais, a saber, O Rio São Francisco, Forte Maurício no Rio São Francisco e Cachoeira de Paulo Afonso, a primeira datada de 1638 e as demais de 1647, podem ser discernidos artifícios e elementos compositivos que evidenciam, por um lado, o caráter documental e, por outro, os aspectos inventivos daquelas imagens produzidas por Post ora in loco, ora quando de seu retorno à Holanda. Sob uma perspectiva documental, compreende-se que a construção da imagem está fundamentada no exercício da observação, no estudo e no registro minucioso dos elementos de um espaço determinado, que seriam informados de modo descritivo sobre a superfície da tela. Concomitantemente, um conjunto de artifícios compositivos pode ser identificado em tais representações, de modo que poderemos compreendê-las - em caráter complementar - segundo a noção de paisagens possíveis ${ }^{1}$, seja tomando um lugar concreto por elemento cenográfico, seja simulando a concretude de um lugar. Sob essa perspectiva, a imagem configura a uma só vez documento e artifício, registro científico e representação pictórica.

\section{Penedo, um lugar concreto}

O Rio São Francisco nasce na Serra da Canastra, em Minas Gerais, e, após estender-se por 2.863 quilômetros, encontra, por fim, o Oceano Atlântico nas alturas do município de Piaçabuçu, Alagoas. O Velho Chico, como é chamado, constitui imponente marco fronteiriço entre aquele estado e o de Sergipe, banhando seus territórios sertão adentro. Diz-se que Américo Vespúcio teria navegado em sua foz em 1501 e em 1502. Em sua segunda viagem, o proeminente navegador batizaria o rio em homenagem a São Francisco de Assis, santo festejado em tal circunstância. Opará, o "rio-mar" dos povos endêmicos, foi desde o século XVI caminho de entrada para as terras em exploração, que viriam a ser disputadas entre portugueses e holandeses.

Às suas margens, entre os diversos povoados que se constituíram nas sucessivas camadas de tempo, está erigida a cidade de Penedo, localizada a quarenta quilômetros da costa. Ela foi qualificada como muito leal e valorosa por Henrique Halfeld 
(1860), a quem se deve a informação de que começou a ser povoada em 1555, quando da chegada do português Duarte Coelho Pereira, primeiro donatário da Capitania de Pernambuco. Penedo era, naquela época, considerada porta de entrada para o sertão e foi, por tal razão, alvo da atenção da Companhia Neerlandesa das Índias Ocidentais², que a invadiu em 1637. Na Vila São Francisco, como era chamada no século XVII, os holandeses instalaram o Forte Maurício, assim designado em homenagem ao Conde João Maurício de Nassau-Siegen (1604-1679), administrador dos territórios conquistados pela Holanda no Nordeste brasileiro.

A Vila São Francisco e o Forte Maurício, que constituíam a fronteira austral dos territórios neerlandeses, foram descritos pelo desenhista, pintor e gravador Frans Post (1612-1680) em 1638 na obra intitulada O Rio São Francisco ${ }^{3}$ (Fig. 1). Uma das poucas obras realizadas in loco pelo artista que permaneceu no Brasil entre 1637 e 1644, tal pintura pode ser abordada - sob perspectiva documental - como uma representação topográfica precisa. Ela configura uma das primeiras tentativas de construção e de assimilação da natureza brasileira, elaborada por um artista profissional (OLIVEIRA, 2005).

\section{Um empreendimento científico no século XVII}

Frans Janszoon Post, nascido em Haarlem, Holanda, tinha vinte e cinco anos de idade quando veio ao Brasil como pintor oficial da comitiva de intelectuais e artistas, trazida pelo Conde de Nassau. Especula-se que teria sido indicado ao Conde por seu irmão, o arquiteto Pieter Post, que mantinha relações profissionais com Nassau. Tendo partido da Europa em outubro de 1636 e chegado a Recife em janeiro do ano seguinte, a comitiva era composta pelas figuras de Georg Marcgraf (astrônomo e naturalista), Willem Piso (médico e naturalista), Albert Eckhout (pintor), Frans Plante (latinista e poeta), Willem Glimmer (explorador que atravessou as florestas além do Rio São Francisco), Jacob Rabb (que viveu entre os Tapuias para aprender seu idioma e tornar-se intérprete), Zacharias Wagener (soldado e pintor amador que já residia no Brasil), entre outros. Contando com a presença de tais personagens, a comitiva configurava uma missão científica que, na melhor tradição descritiva holandesa, deveria não apenas registrar os feitos neerlandeses no Novo Mundo, como traduzi-los para que houvesse condições de divulgá-los entre as cortes europeias ${ }^{4}$.

Dessa empreitada resultaram paisagens, retratos, naturezas-mortas, cartografias, observações astronômicas, descrições da fauna, da flora, dos povos nativos e anotações

\footnotetext{
2 Ao lado da já existente Companhia Neerlandesa das Índias Orientais, foi fundada a Companhia Neerlandesa das Índias Ocidentais em 1621 com fins mercantilistas, de comércio, implantação de colônias agrícolas e pirataria.

30 título da obra consta no catálogo do Museu do Louvre (Coleção Luís XIV), embora também seja conhecida como Rio São Francisco e o Forte Maurits (SOUSA-LEÃO, 1973, p. 54-55).

4 Associa-se, também, ao empreendimento de Maurício de Nassau o projeto de colonização dos territórios conquistados no sentido de constituir uma nova civilização. O Conde previa o desenvolvimento da agricultura e da indústria com o objetivo de tornar aquele novo Estado autossuficiente - projeto para o qual seria necessário, entre outras coisas, o estabelecimento de boas relações com os portugueses e os indígenas, tolerância religiosa e o melhoramento das condições higiênicas. E, apesar de a Companhia Neerlandesa das Índias Ocidentais exigir a conquista de terras, e não reformas internas nos territórios já conquistados, Nassau construiu na Ilha de Antônio Vaz, Recife, sua casa - chamado Palácio de Friburgo, conectado ao continente por canais e pontes. Em torno do Palácio mandou construir também um vasto jardim (botânico e zoológico), onde eram reunidos espécimes vegetais e animais (diversos deles regalados a Nassau pela população local), observados e registrados pelos especialistas da comitiva. Ali também eram realizados estudos da medicina tropical, posteriormente reunidos na obra de Piso e Marcgraf. Em uma das torres Palácio estava instalado um observatório astronômico (o primeiro da América), onde eram realizadas observações e registros. No interior do edifício havia uma vasta sala que funcionava como Museu e Biblioteca, onde Nassau reunia os artefatos trazidos das expedições pelos exploradores, a fim de que fossem estudados, descritos e reproduzidos pelos artistas e cientistas que compunham sua comitiva. A llha de Antônio Vaz, devido às edificações implantadas por Nassau, foi denominada Cidade Maurícia pelos habitantes locais (REVIGLIO, 1972).
} 
sobre medicina. Os conhecimentos enciclopédicos acumulados acerca da natureza - que podia, então, ser lida e interpretada pelo homem - foram, em um segundo momento, organizados em coleções que informavam sobre o Novo Mundo. Títulos diversos seriam publicados a partir dos conhecimentos reunidos em tal empreendimento, como é o caso de História dos feitos recentemente praticados durante oito anos no Brasil e noutras partes sob o governo do ilustríssimo João Maurício Conde de Nassau, etc. [...] (1647), organizado por Gaspar Barlaeus sob encomenda de Maurício de Nassau e composto por gravuras de Frans Post. Nesse conjunto consta, igualmente, História Natural do Brasil $^{5}$ (1648) , reeditado sob o título História Natural e Médica das Índias Ocidentais (1658), cuja autoria é partilhada por Willem Piso e Georg Marcgraf. Tais obras foram financiadas por Nassau e contêm ilustrações atribuídas a Marcgraf6.

Outro exemplar é o Teatro das Coisas Naturais do Brasil ${ }^{7}$ (1669), organizado em quatro volumes pelo médico Christian Mentzel a pedido de Frederico Guilherme I, Eleitor de Brandemburgo. Este recebeu, em 1652, do Conde Maurício de Nassau certo número de estampas, sendo a maioria atribuída a Albert Eckhout. O material coletado passou por um processo de classificação para que pudesse ser incorporado à Kunstkammer e à biblioteca de Frederico Guilherme I (GESTEIRA, 2004). São notáveis, de igual modo, diários ilustrados, como o de Caspar Schmalkalden, alemão que chegou ao Brasil 1642 e que teria participado da expedição ao Chile realizada ainda naquele ano. Seu diário ficou conhecido como Viagem de Amsterdam à Pernambuco no Brasil (1642-1649). Outro exemplar é Thierbuch, de Zacharias Wagener, composto por desenhos de plantas e animais, tipos étnicos, paisagens e vistas de vilarejos (ALBERTIN, 1985).

A missão científica coordenada por Nassau assinala, desse modo, o andar de um processo de dessacralização da Natureza, que a transformava em objeto de conhecimento adquirido por intermédio da observação. Aqui, o sentido primordial é o da visão, cuja experiência deveria ser descrita da forma mais precisa possível pelo observador, fosse este um artista ou um cientista. Nesse contexto, representação pictórica e ciência possuíam como procedimento comum a observação, ao passo que a arte desempenhava uma função documental - caráter por muito tempo qualificado como inferior pela historiografia da arte (ALPERS, 1987). Tal qualidade ficou manifesta nos registros (sobretudo, ilustrações e mapas) de disciplinas que seriam, gradualmente, definidas sob os termos da botânica, da zoologia, da geografia e da etnografia no processo de especialização dos saberes.

\section{Uma paisagem cartográfica}

O quadro de cores sóbrias produzido por Frans Post em 1638, designado 0 Rio São Francisco (Fig. 1), retrata um corpo hídrico em sua imensa horizontalidade e amplitude, qualidades que são equilibradas pela verticalidade de um cacto posicio-

\footnotetext{
5 A obra de Piso e de Marcgraf é de grande valor histórico. Sabe-se que Carlos Lineu, fundador do sistema classificatório no século XVIII e autor da obra Systema Naturae (1758), empregou diversos nomes de animais e de plantas brasileiros derivados daquela obra (ALBERTIN, 1985)

6 Idem.

7 A obra em questão foi reencontrada na Polônia na década de 1970 sob o nome Libri Picturati A 32-38, pois a coleção de desenhos brasileiros foi incorporada, no século XIX, a uma coleção maior de manuscritos ilustrados, designados Libri Picturati. Atualmente, encontra-se na Biblioteca Jagelônica da Cracóvia, Polônia. Não há consenso sobre a autoria das imagens do Teatro das Coisas Naturais do Brasil. Alguns autores atribuem os desenhos a Frans Post, enquanto outros a Albert Eckhout. Também se considera a possibilidade de que as gravuras contidas na História Natural do Brasil tenham sido feitas sob referência dos desenhos contidos no Teatro (Ibidem).
} 
nado à esquerda. O mandacaru, como é chamado, é uma espécie nativa do Brasil e disseminada pelo semiárido da região Nordeste, cuja designação científica é Cereus jamacuru ${ }^{8}$. Ele é representado por Post com um tronco robusto e característicos frutos avermelhados, disposto em primeiro plano sobre um promontório que decresce para o centro da tela.

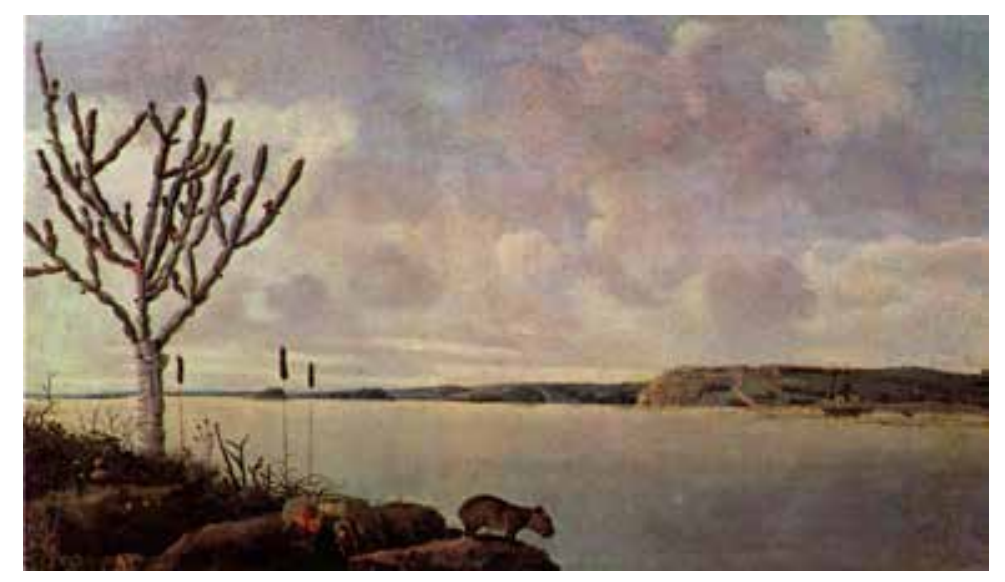

Fig. 1 - Frans Post. O Rio São Francisco (1638).

Óleo sobre tela. $66 \times 88 \mathrm{~cm}$. Museu do Louvre, França.

Também ali, destacados do rio que se estende em segundo plano, outros elementos da flora e da fauna típicos do bioma da Caatinga apresentam-se ao olhar: plantas de baixa estatura e sem folhas, espécies de bromeliáceas (cujas inflorescências são sustentadas por caules rijos de verticalidade austera, sugerindo a imobilidade do ar) e uma capivara9. Ou, queira-se, Hydrochoerus hydrochaeris, segundo a convenção científica. Encontrada às margens do Rio São Francisco, é uma espécie endêmica da América do Sul, cuja alimentação é baseada em gramíneas - estas também representadas pelo artista.

$\mathrm{Na}$ outra margem do rio, à direita do quadro, encontra-se o Forte Maurício na Vila São Francisco (atual cidade de Penedo). A escala diminuta em que se apresentam o barco, a estrada que sobe o morro em direção ao forte e a própria instalação militar, amplia a dimensão do rio que cobre a tela em sentido oblíquo. Sua contraparte é um céu de nuvens abundantes, aqui, amplificado pela baixa linha do horizonte, ambos concebidos nos moldes da tradição holandesa da pintura de paisagem panorâmica, iniciada - segundo Svetlana Alpers (1987, p. 202) - por Hendrik Goltzius (15581617), que "ao invés de trabalhar de memória ou inventar, [...] enfrenta a natureza e trata de captar a dilatada planície holandesa, as granjas, cidades e torres em perfil [...]"10. A paisagem panorâmica, também designada por Alpers (1987) como paisagem cartográfica, configura uma combinação de representação pictórica e de informação geográfica descritiva, esta compreendida não em sentido retórico, senão gráfico.

A representação de Frans Post, nesse sentido, não narra explicitamente um feito humano, tampouco expõe qualquer narração; ela é em si um feito e, sobretudo, descreve os aspectos particulares de um espaço - o terreno visto pelo próprio artista em situação de viajante. Podemos especular que antes de representar tal paisagem

8 A espécie foi descrita por Georg Marcgraf na obra História Natural do Brasil (1648), na qual consta sob a designação lamacarú.

9 A capivara foi descrita também por Georg Marcgraf na obra História Natural do Brasil (1648) como Capy-bara Brasiliensus: Porcus est fluvialitis.

10 Tradução minha: "En lugar de trabajar de memoria o inventar, [...] se enfrenta a la naturaleza y trata de captar la dilatada extensión de la llanura holandesa, las granjas, ciudades e torres perfiladas [...]." 
como uma porção de terra sob posse neerlandesa, Post a registrou conforme se apresentava em seus aspectos naturais: a topografia, a flora e a fauna com detalhes informativos (a saber, o rio em sua serena amplitude, o mandacaru que dá frutos vermelhos, as bromeliáceas com suas inflorescências típicas, a capivara que se alimenta de folhas).

Estes elementos figuram em plano de destaque em conjunção ao céu enquanto os vestígios da ocupação humana se esboçam ao fundo como diminutas edificações sobre a rocheira na Vila São Francisco. A imagem opera, nesse sentido, como evidência visual produzida por uma testemunha ocular: o artista. Aí, constituem-se fragmentos da história fundamentados na informação registrada em representação descritiva ${ }^{11}$. A imagem é tomada como fonte de conhecimento, construída por intermédio da pintura, quiçá a partir de estudos prévios executados pelo especialista, aqui, uma vez mais o artista.

\section{A paisagem como palco de feitos históricos}

O aspecto documental vinculado às imagens produzidas pela comitiva de Maurício de Nassau repousa, especialmente, sobre seus objetivos e fins de uso. Os desenhos e as pinturas produzidas deveriam servir como fonte de informações sobre o que era visto pelos artistas e cientistas nas terras distantes. Uma vez enviadas para a Europa, tais matérias tornavam-se objetos de estudos nas áreas da medicina e da zoologia em especial e compunham coleções mais complexas (ALBERTIN, 1985), reordenadas segundo métodos de classificação estabelecidos por estudiosos daquelas áreas de conhecimento, conforme visto na obra de Willem Piso e Georg Marcgraf, bem como na coleção organizada por Christian Mentzel.

Tal projeto incluía de igual modo a documentação da paisagem enquanto geografia, ao expor o conjunto de seus elementos constituintes - quais sejam, a topografia, a flora, a fauna, os povos e as intervenções humanas. Sabe-se que as paisagens de Frans Post foram, de modo particular, empregadas nos relatos sobre os feitos do Conde de Nassau no Brasil quando de seu retorno à Holanda, seja sob a forma de objetos decorativos (ou raridades, como eram também definidos) expostos em sua residência em Haya (SOUSA-LEÃO, 1973), seja na publicação do título organizado por Gaspar Barlaeus, no qual constam como reproduções reelaboradas sob a técnica da gravura em cobre. Ainda, um terceiro uso dado a elas remonta a confecção de tapeçarias.

\footnotetext{
11 A noção de representação descritiva é tratada por Svetlana Alpers (1987) em oposição à noção de narração. Isto é, uma imagem descritiva não narra feitos humanos (referindo-se a um texto preexistente), senão apresenta informações concernentes a fenômenos diversos observados na realidade, por meio de artifícios (desenho, pintura) que a tornam visível. A imagem configura, desse modo, instrumento de compreensão e conhecimento de determinados aspectos da realidade observada.
} 


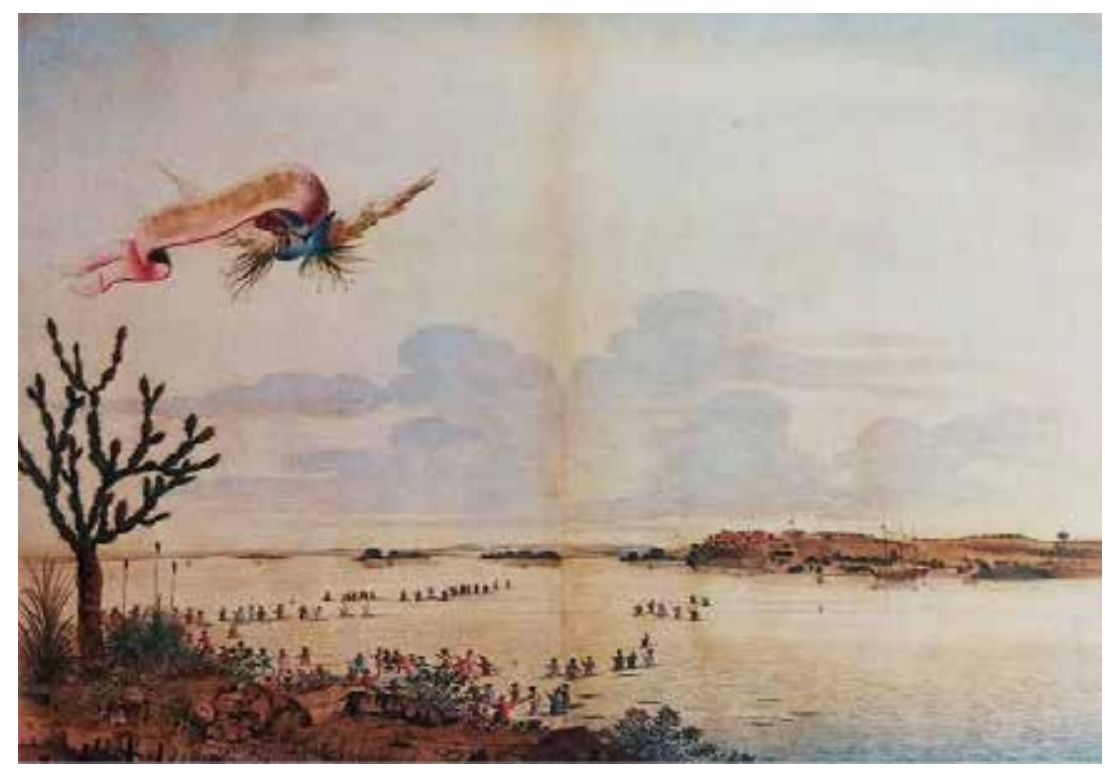

Fig. 2 - Frans Post. Forte Maurício no Rio São Francisco (1647). Gravura em cobre.

Dentre aquelas que figuram no livro de Barlaeus, encontra-se uma variante da pintura O Rio São Francisco (Fig. 1), designada Forte Maurício no Rio São Francisco $(1647)^{12}$ (Fig. 2). A imagem retrata um acontecimento histórico, pois ilustra a fuga dos portugueses da Vila São Francisco após um ataque exitoso das tropas de Nassau. Muito similar à pintura datada de 1638, com exceção de alguns detalhes, a gravura em questão representa um horizonte longínquo e baixo. À distância, na porção esquerda, figuram as ilhotas do rio, destacadas do fundo por sua cor escura e, à direita sobre a rocheira, as edificações da Vila São Francisco. Naquela porção do quadro, distinguem-se agora duas embarcações e, mais acima, uma árvore diminuta totalmente inserida na composição.

Do outro lado do rio, à esquerda em primeiro plano (e como que em espelhamento), está registrada outra árvore. Trata-se do já familiar cacto, no qual, entretanto, não se discernem mais os frutos vermelhos. Sobre o promontório - que, como na pintura, decresce em direção ao centro da imagem - estão representadas, uma vez mais, espécies de bromeliáceas com suas hastes rijas em flor. Sobre a mesma superfície, estão dispostas ainda outras plantas rasteiras. Por detrás das pedras, veem-se, parcialmente, arbustos cobertos por folhas que crescem na margem do rio - exemplares da Mata Atlântica, hoje dizimada pela exploração de madeira e pelo cultivo da cana-de-açúcar. Aqui, a figura da capivara parece ter sido afugentada pela ação que se desenrola no segundo plano, onde um número expressivo de homúnculos atravessa o rio em pequenas jangadas conduzidas a remo. Por fim, o vasto céu é interrompido na porção esquerda, justo acima do cacto, por um pomposo emblema.

12 A mesma composição consta na coleção de trinta desenhos designada Archetipae delineationes brasiliae regionum, sendo a maioria datada de 1645 e elaboradas em pena e bistre ou pincel. Coleção Dr. Hans Sloane, 1753; British Museum, Londres (SOUSA-LEÃO, 1973, p. 153). A datação aqui empregada remonta ao ano de publicação da obra de Gaspar Barlaeus 


\section{Dispositivos para o registro da paisagem}

Ao observarmos mais atentamente as duas representações anteriormente descritas, notamos que se, por um lado, a pintura parece captar um momento de silêncio e de solidão, no qual um animal nativo habita a paisagem despreocupadamente; a gravura, em contrapartida, registra um momento de agitação ao qual a fauna selvagem já não pertence. Embora no caso da gravura a imagem apresente uma ação, ela parece ter sido captada num momento particular (fotográfico, poderíamos dizer por analogia). A pintura, por sua vez e de modo similar, retrata o instante exato em que o mamífero se detém sobre as pedras da encosta enquanto mastiga uma porção de folhas frescas. Nota-se, também, que entre a pintura e a gravura há uma pequena mudança de perspectiva. Enquanto naquela a paisagem está mais próxima do observador de modo que a linha do horizonte se eleva sutilmente; nesta o campo de visão é ampliado e a topografia da paisagem é descrita com maiores detalhes.

É significativo, portanto, que a gravura executada depois do retorno de Post à Holanda, apesar de ilustrar um evento passado e de cunho histórico, contenha informações topográficas ainda mais precisas que a pintura realizada in loco por aquele artista. Ignora-se aqui se Post fora testemunha ocular da fuga dos portugueses da Vila São Francisco, uma vez que o interesse repousa sobre o fato de a imagem ter sido produzida após sua estadia no Brasil, entre 1644 e 1647 (respectivamente, ano de partida e ano de publicação da obra de Gaspar Barlaeus). Isto sugere que Post realizou estudos minuciosos daquela paisagem desde pontos de vista diversos, que resultaram, inicialmente, na pintura de $1638^{13}$ e que foram referenciais na execução da gravura publicada em 1647.

Erik Larsen (1962 apud REVIGLIO, 1972), estudioso da obra daquele artista, lança uma hipótese sobre o possível uso de instrumentos óticos (lentes invertidas descobertas na Holanda daquele século), cuja evidência estaria no plano de fundo relativamente aproximado das pinturas que Post realizou em solo brasileiro. Sousa-Leão (1973), por outro lado, postula que o artista teria antes utilizado o recurso da camera obscura, comumente empregado pelos pintores de paisagens e de cidades para capturar a silhueta das formas a serem representadas. Entretanto, independentemente de qual mecanismo ótico tenha sido utilizado por Post, tais aspectos corroboram a ideia de sua dedicação ao estudo preciso da paisagem, suportado pelo registro dos elementos observados que seriam empregados, posteriormente, em novas composições ora mais, ora menos próximas da realidade concreta. Sob essa perspectiva, Forte Maurício no Rio São Francisco configura uma vista possível de um acontecimento provável. Isto é, um evento que se prova por intermédio de outras formas documentais, em especial relatos como aquele de Barlaeus. Aqui, a imagem retrata o que já constava em forma retórica, ampliando seu valor histórico.

É, além disso, inovador na representação da paisagem brasileira o esquema ao modo repoussoir, empregado por Frans Post desde suas primeiras pinturas da paisagem brasileira. Ao posicionar de um lado uma árvore abundante que introduz uma

\footnotetext{
13 Sousa-Leão (1973, p. 16) é da opinião de que Frans Post indubitavelmente acompanhou Maurício de Nassau em suas campanhas militares. Isto seria evidenciado pela qualidade realista de representações como a da Vila São Francisco em O Rio São Francisco, cujos estudos devem ter sido realizados in loco. O mesmo autor (idem, p. 17) observa, ainda, que o mesmo procedimento é visto nos desenhos feitos por Post da costa africana ocupada pelos neerlandeses. É a partir deles que se conclui que o artista visitou aquele continente ainda em 1644, antes de seu retorno à Holanda.
} 
ampla paisagem de horizonte baixo, o pintor constitui um artifício simples, todavia, tipicamente barroco ${ }^{14}$. Esse tipo de composição se manifesta nas fases seguintes da obra de Post, que repete exaustivamente a temática brasileira em elementos visuais que conheceu e registrou em sua estadia, recombinando-os em um processo de (re) criação de paisagens (OLIVEIRA, 2005). Desse modo, se Post, inicialmente, mantém-se fiel aos estudos realizados in loco, mostra - posteriormente - concessões ao gosto burguês na representação de elementos exóticos (LAGO, 2003). Nessas pinturas, veremos uma diversidade de animais e plantas descritos em primeiro plano, como tamanduás, tatus, jiboias, pássaros, abacaxis e outras bromeliáceas, palmeiras e cactáceas, associados nos planos seguintes a elementos arquitetônicos e figuras humanas (sobretudo, escravos). O emprego de tal esquema de composição reforça o apontamento de Svetlana Alpers (1987), referente ao baixo apelo popular que tiveram as imagens descritivas holandesas do Novo Mundo. Pois, como afirma aquela autora, são os relatos fabulosos, com seus inúmeros elementos exóticos (exaltados por Post em sua fase madura), que seguiam circulando amplamente na sociedade europeia. Os produtos resultantes do empreendimento de Nassau constituiriam, antes, uma coleção principesca utilizada como moeda de troca para elevação do prestígio social do Conde.

\section{0 caso de Cachoeira de Paulo Afonso (1647)}

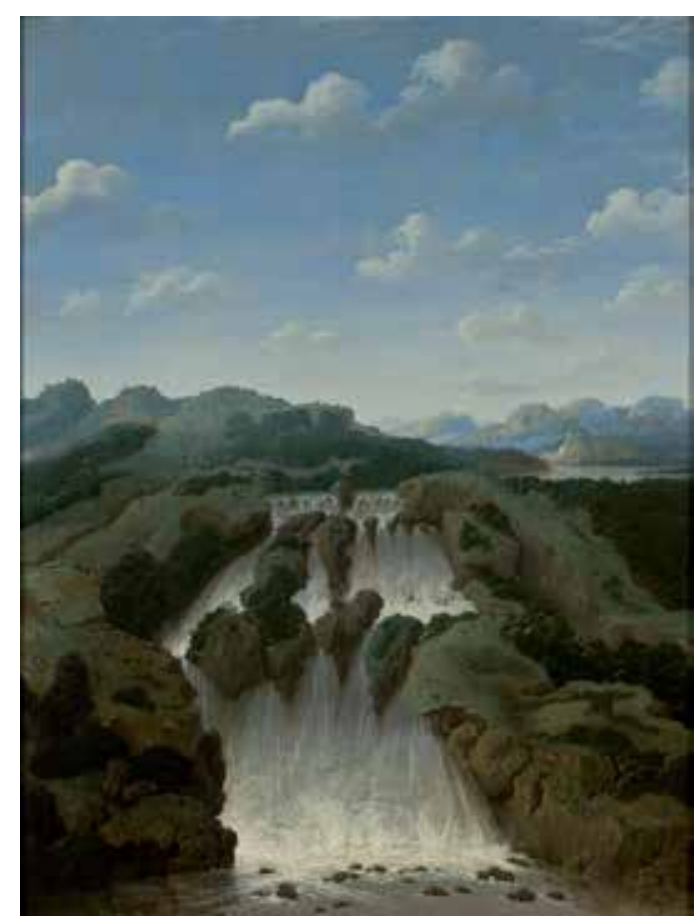

Fig. 3 - Frans Post. Cachoeira de Paulo Afonso (1647). Óleo sobre madeira. $58.8 \times 46 \mathrm{~cm}$.

Museu de Arte de São Paulo Assis Chateaubriand, Brasil.

Outra obra atribuída a Frans Post, datada de 1647 e considerada a primeira pintura realizada após seu retorno à Holanda (SOUSA-LEÃO, 1973), intitula-se Cachoeira de Paulo Afonso (Fig. 3). Diferentemente das representações anteriores, a paisagem é descrita em formato retrato, dividida entre o plano da cachoeira que dá nome à

14 Artifício, frequentemente, empregado pelo também pintor holandês Jacob van Ruisdael (c. 1628 - 1682). 
obra e o céu. Captada frontalmente e de um ponto de vista aparentemente próximo do observador, a queda d'água figura em toda a sua magnificência. Interpelada por rochas robustas, a água cai com violência em dois níveis, forma vapores ao pé da cascata e escorre em direção ao observador na extremidade inferior do quadro. $\mathrm{Na}$ metade superior direita, para além da queda d'água, vemos uma pequena porção do corpo hídrico que se estende na direção do horizonte, onde figuram morros verdejantes. Do céu de um azul intenso, sensivelmente menor que aquele das imagens anteriormente descritas, emana a luminosidade típica do Nordeste brasileiro. Difusas ao fundo, as nuvens brancas adquirem forma à medida que se aproximam da borda superior, compondo um efeito de profundidade.

A Cachoeira de Paulo Afonso é um monumento natural localizado entre dois complexos hidrelétricos no município de Paulo Afonso na Bahia. Rio acima, distante em mais de duzentos quilômetros da cidade de Penedo, já não mais possui as mesmas feições representadas por Post. Suas águas, hoje reduzidas a um filete, correm placidamente entre os imensos rochedos expostos - marcas simultâneas da estiagem severa e da intervenção humana na paisagem natural. Embora tal condição absorva qualquer espectador que compare a pintura do artista holandês ao estado atual daquela paisagem, são os morros no horizonte distante que captam, aqui, nossa atenção. Basta uma visita ao local para que se note a planície quase irreparável do sertão brasileiro, sobretudo, naquela região.

Se da obra O Rio São Francisco (1638) pode-se dizer que representa com precisão a topografia da região de Penedo, conforme vista do outro lado do rio na margem que compete ao Estado de Sergipe, o mesmo não poderá ser postulado sobre a paisagem criada na pintura designada Cachoeira de Paulo Afonso (1647). Apenas os rochedos e a água em abundância se aproximam do que um dia fora a paisagem original daquele sítio. Bastante esquemática e sintética, tal pintura difere das obras anteriores de Post. Como observa Sousa-Leão (1973), ela não parece ter sido feita a partir do natural, senão com base nos esboços de outrem.

Ao contrário das obras anteriores, não temos a impressão de que Post tenha sido testemunha ocular daquela vista. Isto é intensificado, especialmente, pelos morros verdejantes que se sobrepõem ao horizonte, inexistentes na paisagem concreta a que a obra faz referência. Comparativamente às obras anteriores aqui analisadas, nas quais se pode afirmar a precisão topográfica da paisagem representada, Cachoeira de Paulo Afonso parece representar uma mudança de perspectiva na obra daquele artista, que será consolidada de modo efetivo em sua produção mais tardia.

\section{A imagem descritiva como evidência visual}

O termo descrição, normalmente aplicado a textos, deriva do grego ekphrasis. Com função retórica, tal vocábulo referia-se a evocação verbal de pessoas, lugares, edifícios ou obras de arte. Baseado no poder das palavras, linguagem considerada superior às imagens, era emulado na pintura do Renascimento em rivalidade ao ofício dos poetas. Svetlana Alpers (1987, p. 198-199) observa que o termo descriptio - de emprego comum na designação da tarefa dos geógrafos renascentistas, mas não aplicada à pintura - referia-se na geografia a "[...] forma como a imagem, transcrita 
em desenho, fica consignada como um escrito". Desse modo, ao contrário do que ocorre na arte e na literatura, a descrição no campo da geografia e da cartografia "[...] alude não ao poder de persuasão da palavra, senão a uma forma de representação pictórica"15. Alpers propõe que tal concepção, utilizada para definir a informação contida em atlas e em mapas, pode ser estendida à pintura holandesa dos séculos XVI e XVII na medida em que tais manifestações compartilham a intenção de transcrever a realidade para uma superfície visível.

Essa noção contrapunha-se a pintura renascentista italiana que, por sua vez, concebia o quadro como um cenário para a representação de ações humanas significativas. Se da arte nórdica se diz que era descritiva, a arte italiana, por sua vez, era narrativa. Complementarmente, enquanto na Itália do século XVII o desenho (disegno) estava associado ao ato imaginativo em si (imagem ideal), na Holanda ele era compreendido como uma técnica com funções específicas, mais próximo do gênero da escrita, por meio do qual fenômenos observados na realidade eram descritos sobre uma superfície determinada, conforme aponta Alpers (1987, p. 206). Essa tendência - familiar aos geógrafos e aos cartógrafos - gradualmente se infiltrou na pintura de paisagem, constituindo o que aquela autora denomina gênero cartográfico. Tal caráter, vinculado a concepção da descrição como método para documentar a realidade - não por meio retórico, senão gráfico - estará manifesto também nas naturezas-mortas e nos retratos nórdicos.

Além de registro, a imagem (então tomada de prestígio e concebida como uma espécie de linguagem universal) tornou-se veículo de conhecimento acerca de certos aspectos observados da realidade. Tomada como evidência visual no século XVII, a imagem deslocou a autoridade histórica, geográfica e científica. O testemunho histórico, antes baseado em feitos e em ações narrados por intermédio da Bíblia, em mitos, por poetas e historiadores, na forma da tradição mediada pela escritura e pela pintura, passou a fundamentar-se na descrição ilustrada dos fenômenos visíveis, isto é, estaria vinculada antes a uma dimensão espacial do que temporal. Tal concepção encontra par no pensamento do filósofo inglês Francis Bacon (1561-1626), fundamentado na observação, na experimentação e no ordenamento taxonômico da Natureza com o fim de controlá-la e dominá-la em benefício da humanidade. Bastante difundido entre os holandeses, segundo aponta o estudo de Alpers (1987), o programa baconiano para o conhecimento da Natureza concentrava-se no ato da atenção visual e na transcrição exata desse exercício na composição da História Natural.

Tal vertente do pensamento científico - não matemática e baseada na observação - corresponde, no entendimento de Alpers (1987), ao modelo de arte holandesa dos séculos XVI e XVII. A título de contraposição, a arte italiana, a sua vez, admitia um pensamento científico matemático, menos empírico e com antecedentes nas ciências clássicas. A matemática e a arte narrativa (esta expressiva dos mais intensos sentimentos e paixões humanas mediante um repertório tipológico de gestos corporais e veículo de transmissão da tradição), dispunham de prestígio em detrimento de uma arte descritiva, baseada na observação e no experimento.

15 Tradução minha de: "[...] la forma en que la imagen, transcrita en dibujo, queda consignada como un escrito. [...] alude no al poder de persuasión de la palabra, sino a una forma de representación pictórica." 
No entanto, Alpers (1987, p. 117) compreende que se na Itália os artistas se aproximaram do conhecimento científico da Natureza como meio para legitimar e elevar a arte pictórica ao nível da arte liberal (considere-se aqui a perspectiva), na Holanda, diferentemente, arte e ciência possuíam questões comuns oriundas das práticas artesanais tradicionais, a saber: as propriedades da luz, o reflexo, a transparência, as texturas, os espelhos e as lentes. Não foram práticas artísticas inovadoras, argumenta Alpers, senão os usos do ofício arraigados na tradição artesanal nórdica - associados a uma concepção da representação como meio de investigação da realidade - que influenciaram a eclosão das novas ciências naturais.

\section{Lugares possíveis, entre realidade e artifício}

As viagens com fins descritivos (cartográficos, de estudo da flora, da fauna ou de costumes estrangeiros) foram um incentivo tão forte para que os artistas do século XVI deixassem seu país quanto o desejo de visitar Roma, afirma Alpers (1987, p. 192). Tais viagens de exploração e investigação se perpetuaram também em excursões de âmbito doméstico realizadas por artistas no século XVII. Disto seriam exemplares não apenas as estadias do pintor e desenhista Pieter Saenredam (1597-1665) em cidades diversas nas quais retratava igrejas, como também as viagens do paisagista Jan van Goyen (1596-1656), durante as quais registrava em perfis as cidades visitadas.

No caso de van Goyen, o inventário de vistas servia ao fim de compor cenas com elementos de lugares distintos - procedimento que poderia sugerir problemas concernentes à representação da realidade segundo os princípios mais restritos da observação e da descrição. No entanto, Alpers (1987, p. 193) argumenta sobre tal aspecto que, embora as paisagens não representem lugares concretos, elas definem lugares possíveis. Ao manterem um formato topográfico, aplicam e estendem o estilo cartográfico na criação de paisagens imaginárias. Seu caráter descritivo, vinculado ao conhecimento da realidade por intermédio do olhar, não é, entretanto, anulado em detrimento do aspecto compositivo da cena criada pelo artista.

Pintores holandeses, como é o caso de Jan van Goyen, estavam intensamente comprometidos com os pontos de vista a partir dos quais a observação e o registro eram tomados, pois - conforme observa Alpers (1987, p. 194) - a ideia de documentação era inseparável da concepção de representação pictórica. A título de comparação, as obras de van Goyen contrastam com pinturas como Cemitério Judeu (1654-55), de Jacob van Ruisdael (1628-1682), na qual a representação imaginária recebe um tratamento nitidamente emotivo que, neste caso, parece se sobrepor aos aspectos topográficos de paisagens como as criadas por van Goyen. Há, desse modo, uma preocupação primária com a exatidão das formas representadas, e não com os sentidos oriundos dos vínculos estabelecidos entre os elementos que figuram no quadro (ou, ao menos, especulo que tal aspecto ocupe uma posição secundária no pensamento de artistas como van Goyen).

Assim, as três obras de Frans Post aqui analisadas ativam, a meu ver, regimes diversos que trafegam de formas particulares entre realidade e artifício. Enquanto $O$ Rio São Francisco (Fig. 1) mais nitidamente representa um lugar concreto captado pelo artista na posição de testemunha ocular, a gravura Forte Maurício no Rio São 
Francisco (Fig. 2) reativa aquele mesmo espaço a partir de recursos mnemônicos (penso de modo especulativo em esboços tomados in loco, a memória de longo prazo, possíveis percepções registradas em notas como também a própria narrativa de Gaspar Barlaeus). A paisagem transforma-se, no entanto, em cena para a representação de um evento histórico. De documento tomado como evidência visual de certa paisagem, deslocamo-nos para uma imagem tomada como representação de um evento histórico, embora ainda vinculada ao mesmo lugar. Parece-me que de uma imagem a outra, cujas molduras são bastante similares, evidencia-se um processo de criação de paisagem como lugar possível, segundo a noção tomada de Alpers a partir da análise dos procedimentos criativos de van Goyen.

Tal processo torna-se ainda mais evidente quando analisamos a pintura Cachoeira de Paulo Afonso (Fig. 3), onde podem ser discernidos elementos compositivos oriundos de lugares concretos diversos (a cachoeira e os morros, que não pertencem a um lugar concreto comum). É nesse sentido que tal obra parece significativa de uma mudança de perspectiva na produção de Post, considerando-se que em suas obras posteriores a justaposição de elementos diversos não corresponde mais a um princípio descritivo em sentido restrito: sua forma é descritiva, ao passo que seu conteúdo não remete a um lugar concreto. A imagem é, assim, criada na fronteira entre realidade e artifício, uma vez que seus referentes se encontram na natureza tal como observada pelo artista, entretanto recomposta no processo de feitura do quadro. Desse modo, a imagem informa sobre uma diversidade de elementos registrados pelo artista em sua estadia no Brasil, alocando-os sobre uma mesma superfície, isto é, tornando-os visíveis. Contudo, em sentido global, a representação configura um lugar possível no sentido de que não se refere a um lugar real a determinar, senão a um espaço inventado antes próximo de uma definição de ficção.

\section{0 espaço concreto como elemento cenográfico}

Ao compararmos uma vez mais a pintura O Rio São Francisco (Fig. 1) e a gravura Forte Maurício no Rio São Francisco (Fig. 2) a partir do artifício designado repoussoir, vemos que este é alterado em benefício do que ocorre em segundo plano. $O$ que permanece inalterado (ou, apenas sutilmente agregado de informações topográficas) é a paisagem contínua do horizonte, espécie de plano cenográfico, ou moldura, que acolhe ora uma situação de vasta calmaria, ora uma ocasião de tremenda agitação. A margem onde está edificada a Vila São Francisco desempenha, nesse sentido, a função de cena para o que é apresentado nos planos anteriores.

O mesmo se dá com o promontório em primeiro plano que, ao introduzir a vista panorâmica, atua como uma espécie de mostruário minucioso daquilo que pode ser encontrado naquela vasta paisagem. Contudo, enquanto a pintura exibe exemplares de fauna e de flora endêmicos, bem como elementos geológicos; a gravura, em contrapartida, anula a fauna em benefício dos aspectos históricos implicados na representação dos homúnculos em suas jangadas. Embora determinadas por fins diversos, tais imagens compartilham, por assim dizer, a mesma estrutura cênica. $O$ que deve ser ressaltado em cada uma das imagens parece estar implícito no enunciado dos títulos: de um lado, a pintura exalta o rio; de outro, a gravura dá importância 
ao forte militar, situando-o às margens do rio, que é meio para a ação humana e, por isso, figura secundária.

Espaço concreto, a paisagem que figura no horizonte, determina a geografia aqui descrita por meio da pintura e da gravura. Simultaneamente, os elementos que antecedem o plano de fundo (a saber, o rio e o promontório com sua diversidade de formas) constituem vistas possíveis de dois momentos (um específico, outro genérico) circunscritos pela presença do Conde Maurício de Nassau no Brasil. Ambos configuram documentos posto que contêm informações pertinentes a um espaço-tempo político, cultural e social que se recompõem a partir da imagem como objeto histórico e da representação como evidência visual. Tal aspecto documental pode, no entanto, ser compreendido como artificioso. $O$ registro encena a realidade em sua própria condição de representação ${ }^{16}$.

A mesma moldura, por assim dizer, comporta dois tipos diversos de registro. Um é temporal, específico, representação de um feito histórico; o outro, espacial, genérico, cartográfico. Este, representativo da estrutura descritiva da pintura $O$ Rio São Francisco, é revisitado por Post na gravura Forte Maurício no Rio São Francisco e é tal estrutura que comporta o registro dos feitos humanos de modo que descrição e narração encontram-se justapostas num mesmo modelo representacional. Na sobreposição de um evento histórico ao lugar concreto, este se torna cena, ao passo que o registro é encenado na forma de uma imagem.

No entanto, o testemunho histórico aqui tem por base o lugar, e não os feitos ou as ações humanas - característica expressiva da pintura histórica holandesa do século XVII, segundo leitura de Alpers (1987, p. 228). Ao invés da representação do drama das vicissitudes humanas, Post construiu uma descrição ilustrativa do lugar onde o feito histórico ocorreu. O artista não remete ao poder dos holandeses, ao possivel enfrentamento dos corpos, ao agir e sofrer dos sujeitos, que caracterizariam a narração histórica; inscreve, antes, pequeninas figuras, os portugueses, em sua passagem por aquela grandiosa paisagem. Nesse sentido, a representação histórica na obra de Frans Post foi construída de modo descritivo e objetivo em acordo com o pensamento científico vigente na Holanda do século XVII por influência do pensamento de Francis Bacon.

\section{Uma geografia idealizada}

Cinco anos após ter deixado as terras brasileiras, Frans Post se manteve constante à temática das paisagens daquele mundo distante. Segundo um modo descritivo, o artista pintava a partir do repertório de formas captadas em esboços e registros coletados em suas viagens. Entretanto, uma vez desvinculado do projeto científico do Conde de Nassau, também se abolia a exigência pela exatidão das imagens produzidas, tal qual vistas pela testemunha ocular. Os olhos europeus, ávidos pela visibilidade do Novo Mundo, não exigiam retratos exatos do Brasil, senão cenas que alimentassem sua curiosidade e seu imaginário acerca daquelas terras. A exuberância da paisagem como descrita na pintura Cachoeira de Paulo Afonso, embora não representativa de um locus concreto, certamente se mostrou atrativa ao gosto neerlandês e, sobretudo, rentável ao artista.

$16 \mathrm{Ou}$, ainda, conforme propõe Oliveira $(2005$, p. 25), tais imagens representam um mundo exótico criado como registro teatralizado do real. 
A pintura em questão registra, nesse sentido, uma geografia idealizada. Ela parece ter sido montada a partir da justaposição de elementos de origens diversas na composição de uma nova imagem. O efeito descritivo marca a vista frontal da queda d'água, apresenta os elementos de uma cena singular, situada em pleno sertão brasileiro. Informa sua magnitude e a topografia do espaço, que ocupam a inteireza do quadro na ausência de qualquer elemento humano. É a natureza brasileira (idealizada) que é evocada em tal pintura. Há, no entanto, uma interdição entre o título e a representação.

O que a imagem dá a ver não é de fato a Cachoeira de Paulo Afonso. O título da obra e o nome dado ao lugar impelem a que busquemos equidade de sentidos entre a paisagem representada e o lugar concreto. A representação, todavia, cria uma cena que aparenta possuir um equivalente na natureza. Ela produz efeito de realidade não apenas em razão de seus aspectos descritivos, mas também da designação que é atribuída ao quadro. O título nos diz: "Esta é a Cachoeira de Paulo Afonso". Não obstante, o horizonte remete a outra cena, um lugar qualquer ainda por definir. É ele que denuncia o registro preciso como imagem artificiosa.

Também a figura do autor do quadro, isto é, o pintor em sua função de artista viajante - suposta testemunha ocular das paisagens que expõe sob a forma de representações - contribui para o caráter realista da obra Cachoeira de Paulo Afonso. Aqui, convenção e crença determinam a imagem como registro. Entretanto, sob outra perspectiva, tomar a pintura como documento implica também colocar-nos incessantemente diante da catástrofe, aquela da qual é representativo o estado atual do locus concreto. A imagem pode, então, ser tomada como analogia. Mais além, a representação é sempre ainda, até mesmo para nós, forma exótica, representante ou não de um lugar concreto. Mas, sobretudo, conquanto a paisagem descrita por Post configure um lugar qualquer, construído em imagem, ela é um lugar possível em uma terra distante: ora o passado, ora o imaginário do viajante.

\section{Considerações finais}

A mudança na visão paisagística do Brasil na obra de Frans Post acompanha um clima de revoltas e antecipa, de certo modo, uma situação militar de difícil reversão para a Holanda. Em 1654, os assuntos neerlandeses se encerrariam no Nordeste brasileiro. De uma perspectiva geográfica como representada na pintura O Rio São Francisco (1638) (Fig. 1), Post emprega uma perspectiva histórica conforme expressa no conjunto de gravuras que compõem a obra de Gaspar Barlaeus, aqui representada pelo exemplar de O Forte Maurício no Rio São Francisco (1647) (Fig. 2). Finalmente, na obra Cachoeira de Paulo Afonso (1647) (Fig. 3), o pintor recorre a uma forma bastante distinta de representação da paisagem ao criar uma cena que antecipa, poderíamos dizer, as paisagens românticas do século XIX.

Aqui, contudo, não há figuras humanas (como recursos ao modo repoussoir) inseridas na composição. Ao contrário, o único espectador da natureza não está inserido nela; ele contempla a grandiosidade representada sobre a tela a partir de uma posição externa. Ninguém jamais fora testemunha ocular daquela paisagem encenada por Post - tal é sua condição. A distância entre o lugar concreto e a 
imagem que a ele remete é similar àquela que se interpõem entre o artista e sua temática. A saber, as paisagens ultramarinas de um já distante Brasil, presente para o artista apenas como imagem e imaginário na confluência de registros e de memórias. Entre geografias e etnografias descritivas, testemunhas oculares supostas e registros fragmentados, Frans Post - já do outro lado do oceano - representaria elementos reais em espaços imaginados e construídos. Dito de outro modo, o artista comporia paisagens possíveis.

\section{Referências}

ALBERTIN, Petronella J. Arte e ciência no Brasil holandês - Theatri rerum naturalium brasiliae: um estudo dos desenhos. Revista Brasileira de Zoologia, São Paulo, v. 3, n. 5, p. 249-326, jun. 1985.

ALPERS, Svetlana. El arte de describir. El arte holandés en el siglo XVII. España: Hermann Blume, 1987.

BARLAEUS, Caspar. História dos feitos recentemente praticados durante oito anos no Brasil. Recife: Fundação Cultura Cidade do Recife, 1980.

BELLUZZO, Ana Maria. O viajante e a paisagem brasileira. Revista Porto Arte, v.1, n.1, p. 41-58, jun. 1990.

Metalivros, 1999.

O Brasil dos viajantes. 2. ed. Rio de Janeiro: Objetiva/

BURKE, Peter. Testemunha ocular: história e imagem. Bauru: EDUSC, 2004.

DIENER, Pablo; COSTA, Maria de Fátima. A Arte de Viajantes: de documentadores a artistas-viajantes. Perspectivas de um novo gênero. Revista Porto Arte, v.1, n.1, p. 75-90, jun. 1990.

GESTEIRA, Heloísa Meireles. O Recife holandês: história natural e colonização neerlandesa (1624-1654). Revista da SBHC, Rio de Janeiro, v. 2, n. 1, p. 6-21, jan./jun. 2004.

HALFELD, Henrique Guilherme Fernando. Atlas e relatório concernente a exploração do Rio de São Francisco - desde a Cachoeira da Pirapóra até o Oceano Atlântico, levantado por ordem do governo de S. M. I. o Senhor Dom Pedro II. Rio de Janeiro: Lithographia Imperial, 1860.

LAGO, Bia Côrrea (Org.). Frans Post e o Brasil Holandês na coleção do Instituto Ricardo Brennand: catálogo da exposição. Recife: Instituto Ricardo Brennand, 2003. 
OLIVEIRA, Carla Mary. O Brasil seiscentista nas pinturas de Albert Eckhout e Frans Janszoon Post: documento ou invenção do Novo Mundo. In: ATAS DO CONGRESSO INTERNACIONAL ESPAÇO ATLÂNTICO DE ANTIGO REGIME: poderes e sociedades. Lisboa: Universidade de Lisboa, 2005.

REVIGLIO, Laura. Frans Post: o primeiro paisagista do Brasil. Revista do Instituto de Estudos Brasileiros, São Paulo, n. 13, p. 1-33, 1972.

SOUSA-LEÃO, Joaquim de. Frans Post 1612-1680. Amsterdam: A. L. van Gendt, 1973. 